\title{
Third Head of the Biceps Brachii Muscle and a Communication between the Musculocutaneous and Median Nerves: A Case Report
}

\author{
Caroline Dussin $^{1} \quad$ Lucas Oliveira Moyses $^{1}$ Sávio Lana Siqueira ${ }^{1,2,3}$ \\ ${ }^{1}$ Department of Anatomy, Faculdade de Ciências Médicas de Minas \\ Gerais, Belo Horizonte, MG, Brazil \\ 2 Department of Surgery, Universidade Federal de Minas Gerais, Belo \\ Horizonte, MG, Brazil \\ ${ }^{3}$ Department of Surgery, Universidade Federal de Ouro Preto, Belo \\ Address for correspondence Caroline Dussin, Medical Student, \\ Departamento de Anatomia, Faculdade de Ciências Médicas de Minas \\ Gerais (FCMMG), Alameda Ezequiel Dias, 275, Belo Horizonte, MG \\ 30130-110, Brasil \\ (e-mail: carolinedussin@gmail.com).
} Horizonte, MG, Brazil

J Morphol Sci 2019;36:51-54.

\section{Introduction}

The brachial plexus (C5-T1 vertebrae) is a cervical swelling of the spinal cord that originates the nerves that supply the upper limbs. The communications between these 5 spinal nerve roots ( $\mathrm{C} 5-\mathrm{T} 1$ vertebrae) originates 3 nerve fasciculus, which differ in terminal branches, including the musculocutaneous nerve (Mc) (C5-C7 vertebrae) and the median nerve (Me) (C5-T1 vertebrae).

The Mc is formed by the terminal portion of the lateral fasciculus and is responsible for the motor innervation of the muscles of the anterior compartment of the arm and for the sensory innervation of the lateral skin of the forearm. ${ }^{1}$

The Me is formed by a root from the lateral fasciculus and by a root from the medial fasciculus and is responsible for the motor innervation of a great part of the flexor muscles of the forearm, of half of the intrinsic muscles of the thenar palm, and of the skin of the palm. ${ }^{1}$

Therefore, the Mc and the Me nerves do not usually communicate (-Fig. 1).

The biceps brachii muscle has two origins, one in the supraglenoid tubercle, and another in the coracoid process, both located in the scapula, and their bellies unite to form a common tendon that inserts into the radial tuberosity and into the forearm fascia, through the aponeurosis of the biceps brachii. ${ }^{1}$

However, anatomical variations have been reported in the literature, with the occurrence of communications between the Mc and the Me nerves. Supernumerary heads of the biceps brachii muscle have also been reported. ${ }^{2}$

However, it is quite unusual for both of these anatomical variations to occur in the same cadaver and in the same limb. received

November 5, 2018

accepted

November 8, 2018

published online

January 15, 2019
DOI https://doi.org/

10.1055/s-0038-1676860. ISSN 2177-0298.
Copyright $\odot 2019$ by Thieme Revinter

Publicações Ltda, Rio de Janeiro, Brazil
License terms

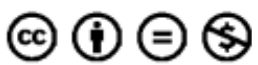



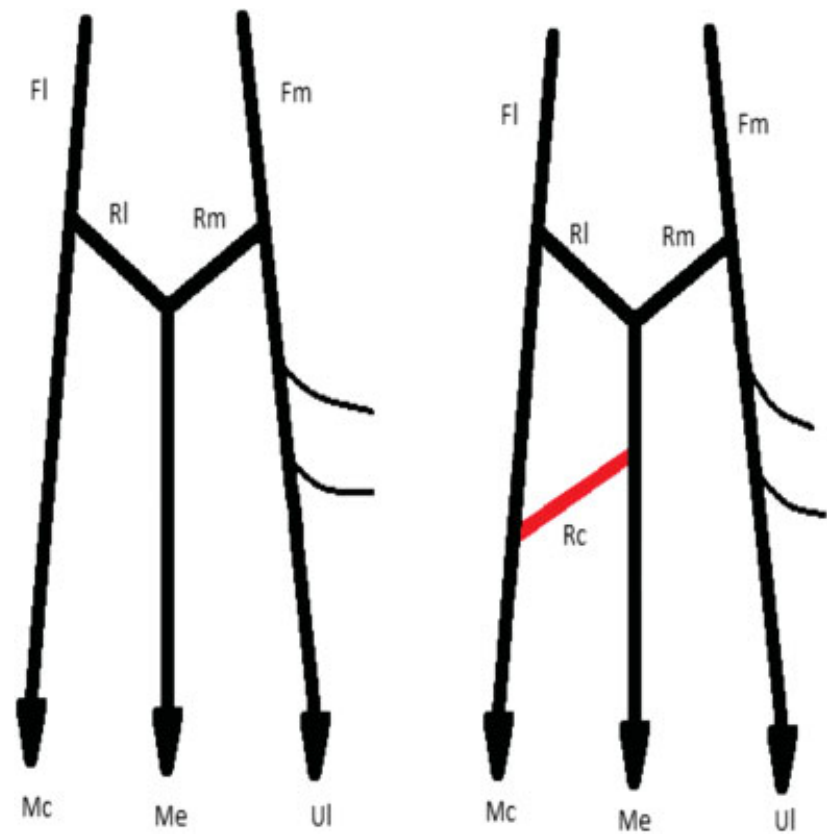

Fig. 1 Left drawing: normal arrangement of nerve fibers. Right drawing: variation presented in the present case report. Fl: lateral fasciculus; Fm: medial fasciculus; Mc: musculocutaneous nerve; Me: median nerve; Rc: communicating branch; RI: lateral root; Rm: medial root.

The aim of the present study is to describe the relationship between multiple anatomical variations found in the right arm of a male cadaver, which were: a communication between the Mc and the Me nerves associated with a third head of the biceps brachii. The occurrence of a third head of the biceps brachii associated with this communication has clinical and surgical importance, and its knowledge can prevent iatrogenic mistakes.

\section{Case Report}

During a routine dissection, the right arm of a male cadaver presented a third head of the biceps brachii muscle. This variation has an incidence of $14.5 \%$ in the Brazilian population $^{3}$ (-Table 1).

The third heads of the biceps were sorted by RodríguezNiedenführ et al (1992), ${ }^{2}$ according to the location of their origins in the humerus. There are three types of humeral heads: superior, inferomedial or inferolateral. It was also reported supernumerary heads arising from the pectoralis

Table 1 Incidence of the Third Head of the Biceps Brachii in Different Populations

\begin{tabular}{|l|l|}
\hline Population & Incidence (\%) \\
\hline Chinese $^{\mathrm{a}}$ & 8 \\
\hline European $^{\mathrm{a}}$ & 10 \\
\hline African $^{\mathrm{a}}$ & 12 \\
\hline Japanese $^{\mathrm{a}}$ & 18 \\
\hline Brazilian $^{\mathrm{b}}$ & 14.5 \\
\hline
\end{tabular}

${ }^{\mathrm{a}}$ Data acquired from Jayanthi et $\mathrm{al}^{11}$.

${ }^{b}$ Data acquired from Santo Neto et $\mathrm{al}^{3}$. major muscle and from the coracoid process. The variation found in this cadaver, however, has its origin in the anterior third of the arm, from fibers coming from the brachial muscle, $18.0 \mathrm{~cm}$ away of the coracoid process of the scapula. It crosses the arm, from medial to lateral, joining its body with the biceps brachii to form a common tendon with this muscle. This third head has $11.0 \mathrm{~cm}$ in length, $1.8 \mathrm{~cm}$ wide, and continues inferiorly deep to the biceps brachii and superficially to the brachialis muscle (-Fig. 2).

Besides, this same arm had a communicating branch between the Mc and the Me nerves. The communication between these nerve was classified by Le Minor $(1992)^{4}$ and by Venieratos et al (1998). ${ }^{5}$ The classification by Le Minor takes into account the height of this communication in the arm and how the fibers are arranged. There are five types:

Type 1: There is no communication between the Mc and the Me nerves.

Type 2: The fibers of the lateral root of the Me nerve go along with the Mc and the head to encounter and fuse with the Me nerve after a certain distance.

Type 3: The fibers of the lateral root of the Me nerve go along with the Mc nerve and, after a certain distance, leave it to finally form the lateral root of the Me nerve. Type 4: Some of the fibers of the Mc nerve run through the lateral root of the Me nerve before merging, finally, in the Mc nerve.

Type 5: There is no development of the Mc nerve and every fiber that should be separated in this nerve is in the Me nerve, and they supply the muscles and the part of the skin that should be innervated by the Mc nerve.

In addition to the classification by Le Minor, there is also the classification by Venierators et al, from 1998, defined according to the relationship between the communicating 


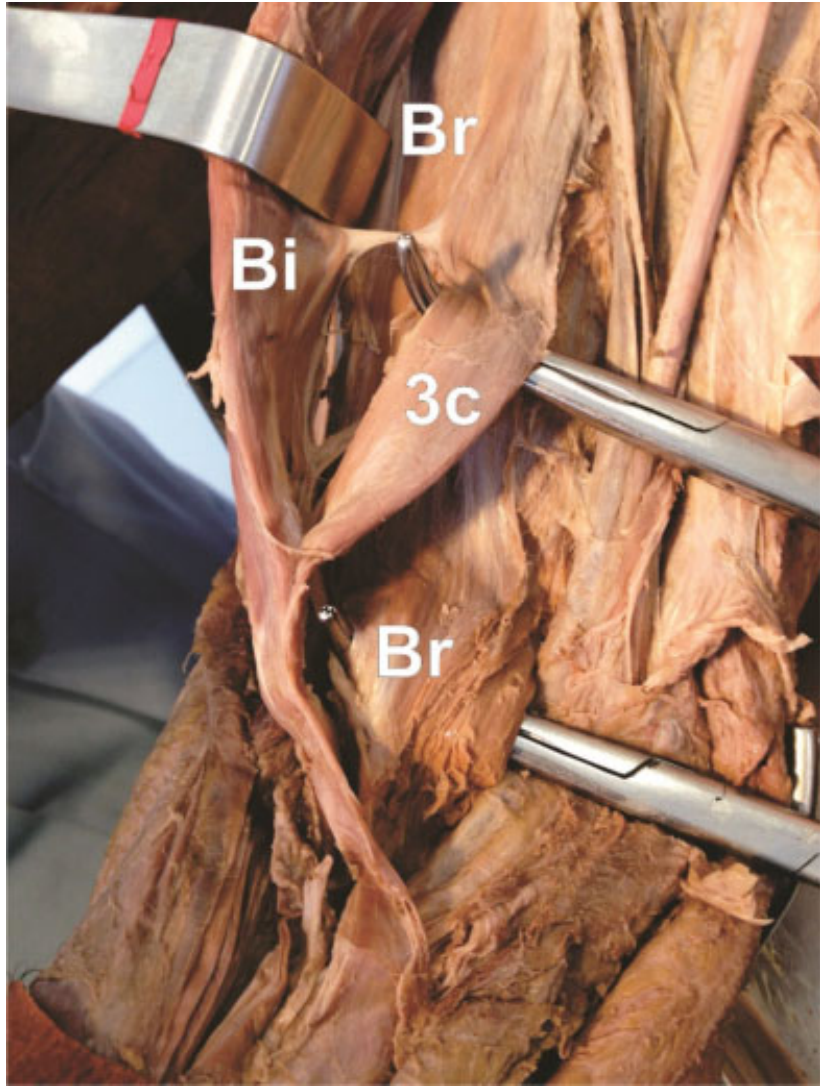

Fig. 2 Bi: biceps brachii; Br: brachial; Me: median nerve; 3c, third head of the biceps brachii.

branch and the coracobrachialis muscle. ${ }^{4,5}$ It is divided into three types:

Type I: The communicating branch is proximal to the drilling of the coracobrachialis muscle by the Mc nerve.

Type II: The communication occurs distal to the perforation of the coracobrachialis muscle by the Mc nerve.

Type III: There is no drilling of the coracobrachialis muscle by the Mc nerve or by the communicating branch.

The measurement of the third head of the biceps and of the communicating branch between the Mc and the Me nerves took as reference the distance from the coracoid process of the scapula. Based on these classification standards in the literature, the variation found in this body is type 2 , according to Le Minor, and type II, according to Veniertators et al.

The communicating branch (Rc) was found $16.0 \mathrm{~cm}$ away from the coracoid process of the scapula drilling in coracobrachialis muscle (the branch's length was $8.0 \mathrm{~cm}$ ). The length of the Mc was $17.5 \mathrm{~cm}$ (from its origin as a terminal branch of the lateral fasciculus, until the fibers that was provied for the formation of Rc). The Me in this cadaver was formed by a lateral root (derived from the lateral fasciculus), with $4.5 \mathrm{~cm}$, and by a medial root (derived from the medial fasciculus), with $3.0 \mathrm{~cm}$. From the location where the Me is formed (from the medial and lateral roots) to where it receives the Rc, the length of the Me was $20.0 \mathrm{~cm}$ (-Fig. 3).

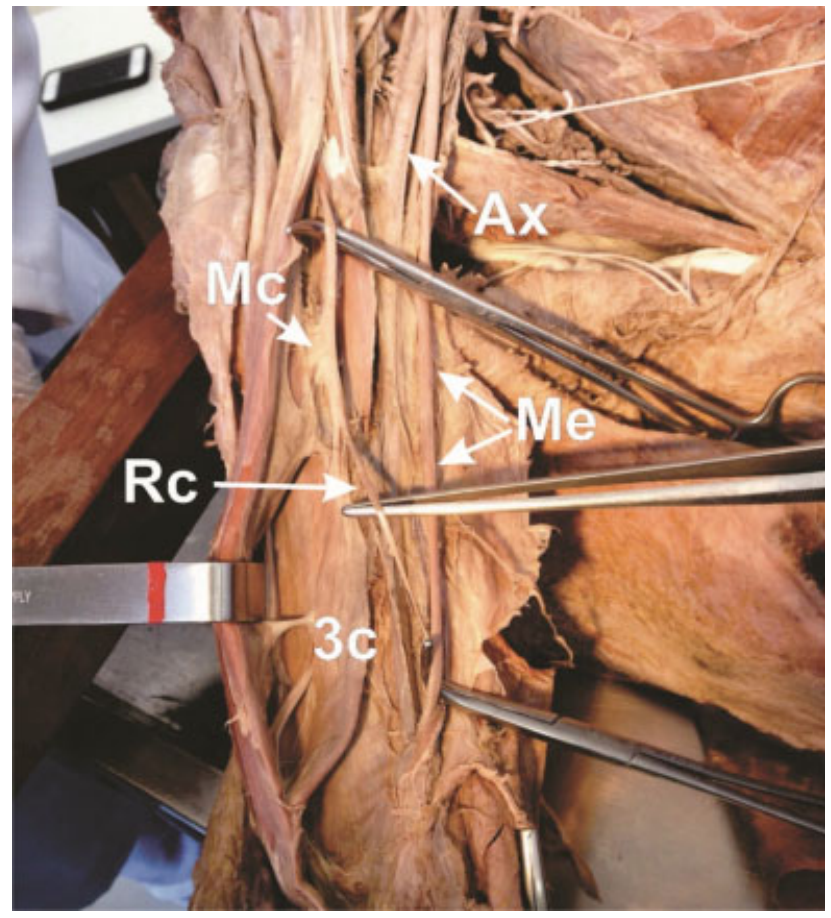

Fig. 3 Ax: axilar Artery; Mc: musculocutaneous nerve; Me: median nerve; Rc: communicating branch; $3 c$ : third head of the biceps brachii.

\section{Discussion}

The presence of a third head of the biceps associated with a variation of the Mc nerve may result from embryonic alterations during the development of the upper limb. ${ }^{2,4,6,7,9}$ The mesenchymal forming muscles of the upper limb are pierced by primary ventral spinal nerve branches, whose contact is required for the mesenchymal condensation to the muscles.

As the development goes on, the somatic mesoderm invades the anlage, producing two condensations, a dorsal one and a ventral one, which will origin, respectively, the supinator-extensor muscle group and the flexor-pronator group. The nerves that invade the anlage of the developing limb avoid or do not penetrate the dense mesenchymal region or tissues with high rates of glycosaminoglycans. The places where a nerve can penetrate will collaborate with the development of muscles by signaling produced by the muscle itself. This may help to explain the mechanism of neuromuscular anatomical variations. ${ }^{6}$

The development of a third head of the biceps brachii can influence these nerve branching patterns, due to the close relationship of the mesenchyme with the primary ventral branches of the spinal nerves. ${ }^{7-12}$ It is speculated that changes in muscle growth regulatory genes, such as Pax 3 and Myf 5, and transcription factors, such as Myo D, may be involved in this kind of variation. ${ }^{11}$

In most cases, the communication between the Mc and the Me nerves, as well as the third head of the biceps brachii, are asymptomatic variations and incidental findings during surgeries or imaging studies. ${ }^{7}$ The third head of the biceps brachii can, however, simulate a soft tissue tumor when it is 
unilateral. ${ }^{6}$ It can also complicate surgical procedures and confuse surgeons; as well as promote vascular and/or nerve compression in the arm, causing ischemia of the irrigation of the territory of the brachial artery and of its branches, or even pinching the Mc, causing paresis and paresthesia in its territory of innervations. ${ }^{7,8,10,11,13}$

The third head may still be responsible for the compression of the Me nerve, which runs through the arm and penetrates the region of the elbow in close relation with the brachial muscle and with the tendon of the biceps, with common symptoms when associated with doubling of the lacertus fibrosus. On physical examination, the compression of the Me can be evidenced by elbow flexion against resistance, with the supinated forearm, which will cause tension in the lacertus fibrosus associated with accessory aponeurosis and a third head of the biceps brachii, triggering neurological symptoms in the nerve territory, similar to pronator syndrome. $^{14}$

The simultaneous presence of the communication between the Mc and the Me nerves and of the third head of the biceps brachii could also increase the incidence of compressive phenomena due to the proximity of these two variations. An hypertrophy of the third head of the biceps brachii that compresses the communicating branch between the Mc and the Me nerves could even simulate carpal tunnel syndrome. It could be difficult to diagnose and it could not be corrected by conventional surgical methods if the possibility of these variations is not borne in mind. ${ }^{7}$ Humeral fractures in patients with a third head of the biceps brachii can be moved depending on the type and location of the fracture and on the presence of fragments. ${ }^{9,11,15}$ Nerve damage from communicating branches between the Mc and the Me nerves may cause weakness in the compartment of the anterior arm, compromising the flexors of the forearm, as well as loss of skin sensitivity on the lateral side of the forearm and on the palm, depending on the fibers that pass through the injured communicating branch.

The third head of the biceps brachii can also generate extra flexion and supination force of the forearm, as well as elbow flexion independent of the position of the shoulder joint. ${ }^{4-6}$ Some authors suggest that, depending on the position of the third head, it can contribute to the pronation of the forearm. ${ }^{16}$ There have been also suggested that acessory heads with an accompanying artery or nerve may be useful in reconstructive surgery with flap removal. ${ }^{11}$

\section{Conclusion}

Due to the frequency of diagnoses and the number of surgical procedures performed in the upper limbs, it is extremely important for orthopedists, surgeons, neurologists, and general physicians to know the anatomical variations described in the present study. The information in the present report, therefore, helps in understanding these variations so that iatrogenic complications can be avoided. ${ }^{7,15}$

Conflicts of Interest

The authors have no conflicts of interest to declare.

\section{References}

1 Moore KL, Dalley AF, Agur AMR. Anatomia Orientada para a Clínica. 7a ed. Rio de Janeiro: Guanabara Koogan; 2014:1114

2 Rodríguez-Niedenführ M, Vázquez T, Choi D, Parkin I, Sañudo JR. Supernumerary humeral heads of the biceps brachii muscle revisited. Clin Anat 2003;16(03):197-203

3 Santo Neto H, Camilli JA, Andrade JC, Meciano Filho J, Marques MJ. On the incidence of the biceps brachii third head in Brazilian whites and blacks. Ann Anat 1998;180(01):69-71 Doi: 10.1016/ S0940-9602(98)80137-4

4 Le Minor JM. [A rare variation of the median and musculocutaneous nerves in man]. Arch Anat Histol Embryol 1990;73:33-42

5 Venieratos D, Anagnostopoulou S. Classification of communications between the musculocutaneous and median nerves. Clin Anat 1998;11(05):327-331

6 Kreilinger JJP, de la Cuadra-Blanco C. J.F. R-V, J.R. M. Four cases of anastomosis between the musculocutaneous and median nerves. Eur J Anat 2007;11(03):193-196

7 Cerda A. Third head of biceps brachii muscle, associated with musculocutaneous and median nerve bilateral communication and with a communicating branch between median nerve roots. Int J Morphol 2014;32(02):510-514

8 Chaudhary P, Kalsey G, Singla R, Arora K. Communication Between Musculocutaneous and Median Nerve - Different Types and Their Incidence in North Indian Population. Indian J Clin Pract. 2013;24 (03):364-371

9 Devi SS, Krupadanam K, Anasuya K, Sreedevi G. Bilateral Occurrence of Additional Heads of Biceps Brachii - A Case report. Int J Res Dev Heal. 2013;1(04):195-199

10 Ilayperuma I, Nanayakkara G, Palahepitiya N. Incidence of Humeral Head of Biceps Brachii Muscle: Anatomical Insight. Int J Morphol 2011;29(01):221-225

11 Jayanthi AA, Elezy MA. Study of Variations in the Origin of Biceps Brachii Muscle in Kerala. Int J Sci Resarch Publ 2012;2 (08): $1-4$

12 Lokanadham S, Devi VS. Anatomical variation-Communication between musculocutaneous nerve and median nerve. Int J Biol Med Res 2012;3(01):1436-1438

13 Poudel PP, Bhattarai C. Study on the supernumerary heads of biceps brachii muscle in Nepalese. Nepal Med Coll J 2009;11(02): 96-98

14 Spinner M. Injuries to the major branches of peripheral nerves of the forearm. J Neurol Sci 1972;141(Mar): ••• Available from http:// linkinghub.elsevier.com/retrieve/pii/0022510X73900865 [Internet]

15 Remya K, Krishnamurthy A, Kavitha K. Communication Between the Musculocutaneous and Median Nerve: Occurrence on both sides. Nitte Univ J Heal Sci. 2011;I(04):55-56

16 Asvat R, Candler P, Sarmiento EE. High incidence of the third head of biceps brachii in South African populations. J Anat 1993;182(Pt 1): 101-104 